\title{
COMPARISON OF RESIDUAL STRESS STATE ON SHEETS FAYING SURFACE AFTER STANDARD AND NACA RIVETING-NUMERICAL APPROACH
}

\author{
Wojciech Wronicz \\ Institute of Aviation, Materials and Structures Research Center, \\ Al. Krakowska 110/114, 02-256 Warsaw, Poland \\ wojciech.wronicz@ilot.edu.pl
}

\begin{abstract}
One crucial characteristic of the aircraft structure are fatigue properties and rivets are usually critical areas in metal airframes due to fatigue cracks nucleation. According to literature, the $N A C A$ riveting method offers a huge increase in fatigue life of riveted lap joints. This paper presents FE simulations of quasi-static riveting on a press for standard countersunk rivets and the $N A C A$ riveting in two configurations: with a normal brazier rivet and a brazier rivet with a compensator. The analyzed configurations have been compared based on the stress courses on the sheets faying surfaces after riveting process. Due to a lack of data, the rivet length and the squeezing force value were assumed for NACA riveting based on FE simulations. The results indicated beneficial influence of the NACA riveting in the outer sheet (with a countersunk) and disadvantageous influence in the inner sheet. This effect was stronger in the case of the rivet with a compensator.
\end{abstract}

Keywords: NACA riveting, fatigue, FE, joints.

\section{INTRODUCTION}

Fatigue properties are one of the crucial characteristic of an aircraft determining its success as they affect directly exploitation costs (direct operating cost). Fatigue properties influence not only the operational life but also determine the frequency and type of the NDT (Non-Destructive Testing) inspections necessary in order to detect cracks before they grow to a size affecting the structural integrity and safety of an aircraft. Operational lifespan is decisive for the depreciation cost. The costs of inspections and maintenance as well as costs connected with taking an aircraft out of service and making it unavailable are huge.

Most metal airplanes are assembled with the use of rivets. At the same time, riveted joints are critical areas of an aircraft structure as fatigue cracks usually initiate near the rivet holes. For this reason, fatigue life of riveted joints directly affects fatigue properties of a whole aircraft.

The fatigue life of riveted joints depends on many factors including loads, geometry of a joint, material, rivet type and riveting method. Many researches and even whole projects have been focused on finding out a way to increase the fatigue life of such joints. It is commonly accepted that for the crack nucleation and propagation decisive is a stress system around the rivet.

At the 1997 ICAF conference, Muller and Hart-Smith presented the paper 'Making Fuselage Riveted Lap Splices with 200-year crack-free fatigue lives' [1]. They had investigated fatigue of 3row countersunk-rivet lap splices, obtaining a 25-fold increase in fatigue life (compared to fatigue 
life of splices riveted with the minimum allowable force) with the use of high riveting force and the NACA riveting method. Despite such promising results, there are only a very few articles devoted to fatigue properties of the NACA riveting. The aim of this work is to investigate benefits offered by this method, namely the influence of NACA riveting on the stress state around rivets, with the use of FE calculations.

\section{NACA RIVETING METHOD}

The idea of the NACA riveting method is shown in Figure 1. The standard countersunk hole is prepared, but a protruding rivet is used instead of a countersunk rivet. The rivet is inserted from the non-countersunk side and squeezed. When a rivet shank is compressed, fill countersunk and form the driven head. At the end of the process, the part of the driven head protruding above the sheet surface is milled.

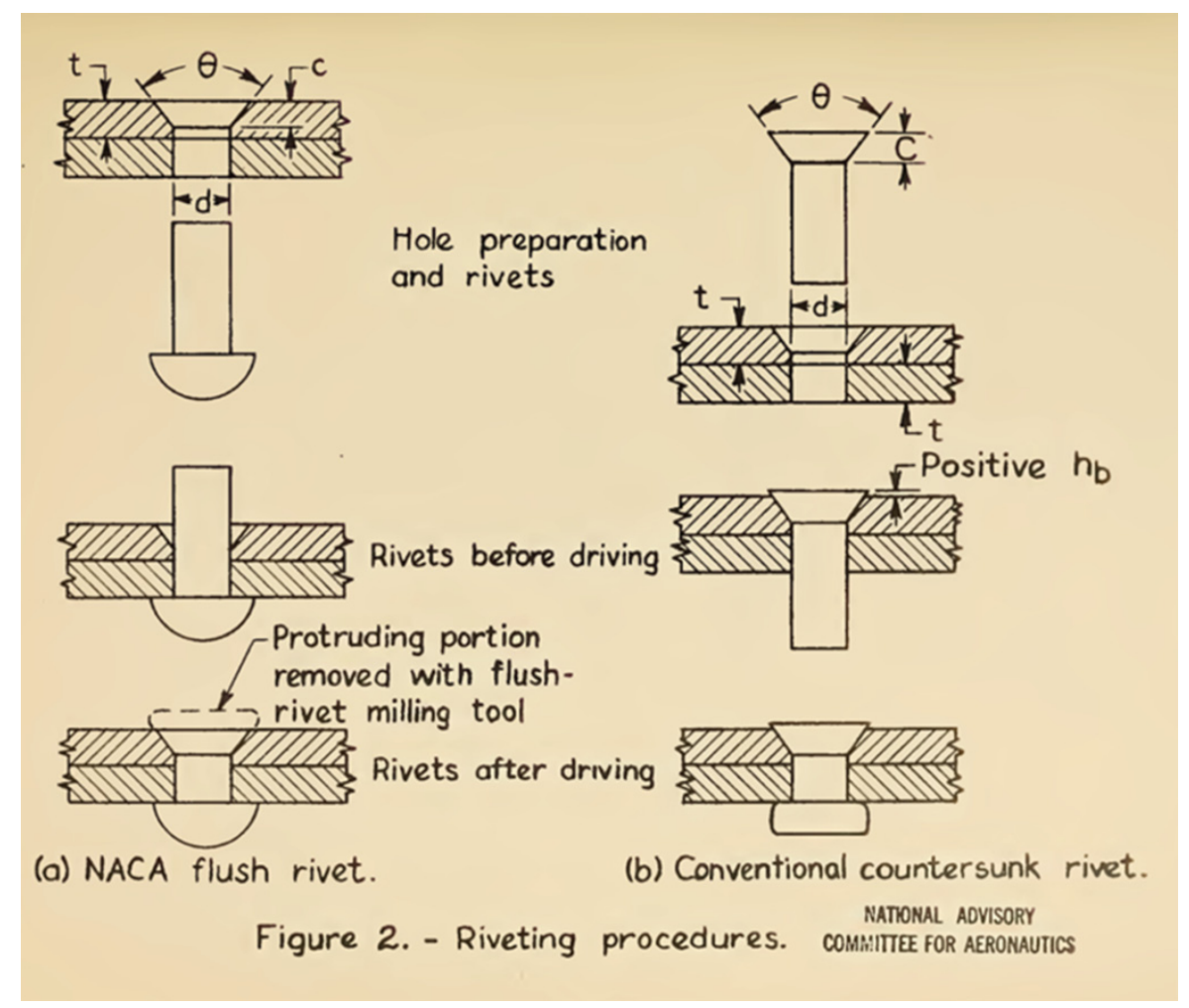

Fig. 1. NACA vs. standard riveting method [2]

The method was developed during the Second World War in the United States and its first description can be found as the NACA wartime report no L-297 (1942) entitled: A study of the tightness and flushness of machine-countersunk rivets for aircraft [3]. The original purpose of this method was not to improve the fatigue performance but to improve the shear strength, the tightness, and the flushness of rivets. There are several NACA Wartime Reports presenting results for joints assembled with the NACA riveting method during the years 1942-1944. One of them [4] focused on the fatigue properties of joints indicating a lower fatigue life of joints riveted with the NACA method compared to some of joints riveted with a standard method. In 1954, Hartman reported superior fatigue characteristics of the NACA riveting in the case of higher loaded joints [5]. Oldersma, in his literature review [6], confirmed this property of the NACA riveting and noticed that this method showed a larger standard deviation compared to the standard riveting. Müller and Hart-Smith in 1997 presented the results of fatigue tests of three-row lap joints in several configurations. The joints where the NACA riveting was used in outer rows reached over 
1 million cycles [1]. The benefits offered by this method were described in [7] by Hart-Smith. The key advantage of the NACA riveting was cold-working of sheets near the faying surface (see Fig. 2), where the cracks usually nucleated.

a)

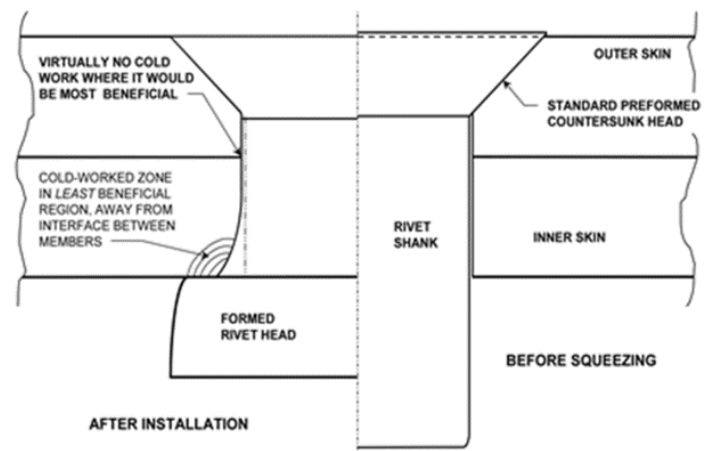

b)

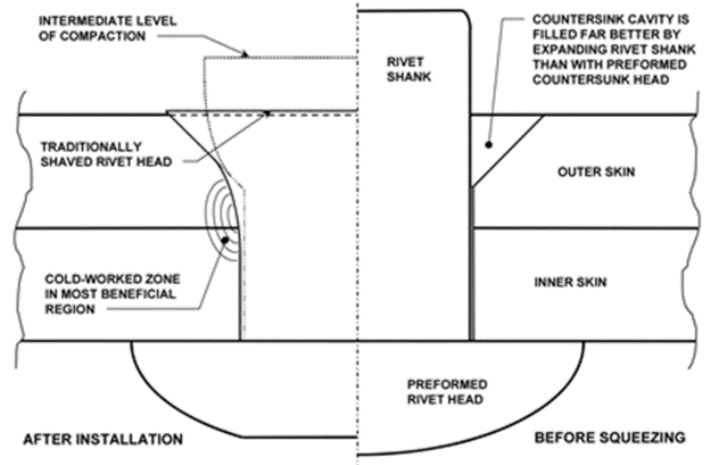

Fig. 2. Comparison of standard (a) and NACA riveting (b) [7]

In the case of the standard configuration, cracks start near the countersunk in the outer sheet at top rows, where they could be detected more easily. When the NACA riveting was used with the same geometry of holes (countersunk in the outer sheet) cracks started in the inner sheet (without countersunk) at bottom row, where it was more difficult to detect them. Müller and Hart-Smith also presented the configuration where NACA riveting was used in both outer rows but at bottom row the countersunk was used in the inner sheet. In this case, the joint was antisymmetric and both outer rows were loaded in the same way (see Fig. 3). Fatigue life was higher but a disadvantage of this solution were protruding rivet heads on the outer surface, which increases an aerodynamic drag.

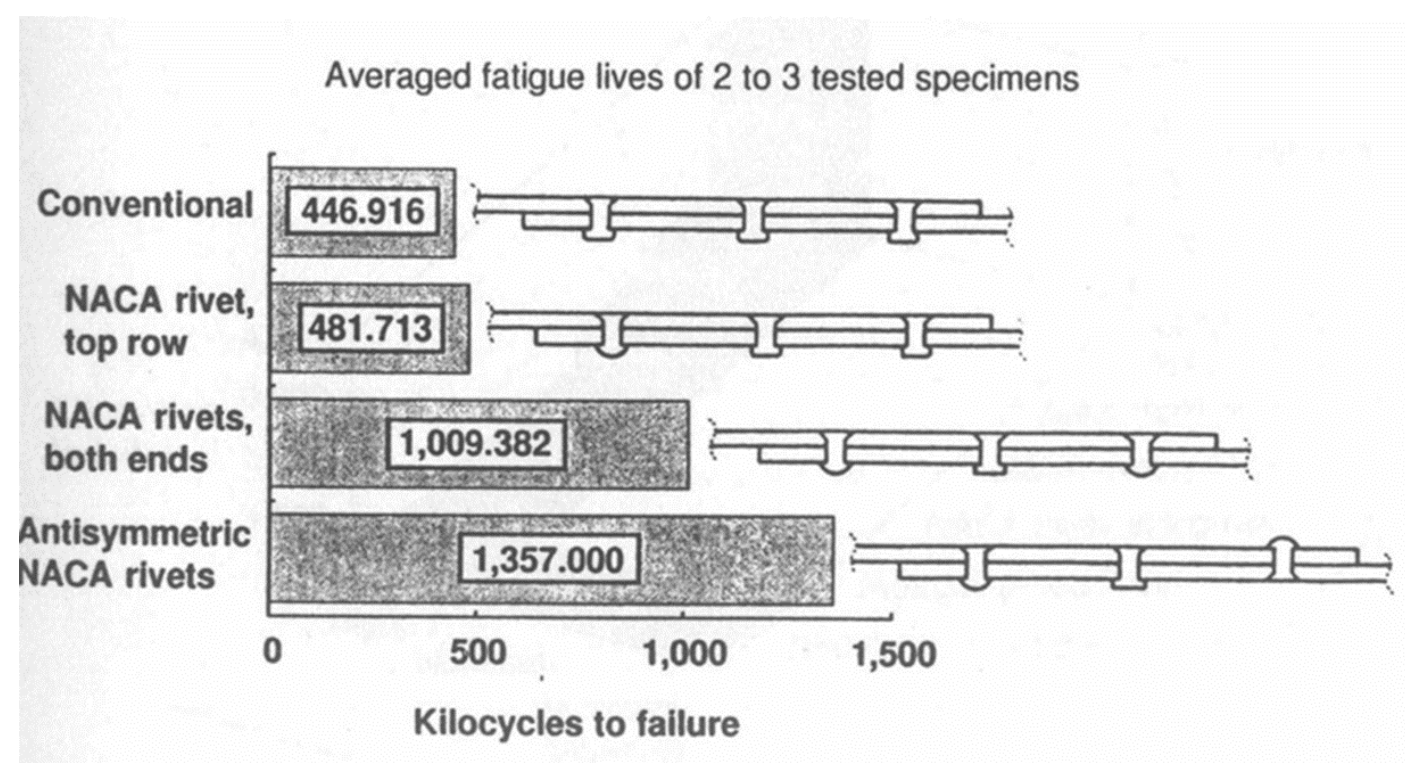

Fig. 3. Effect of NACA rivet installation [1]

\section{THE CONCEPT}

The aim of the paper is to present a simple analysis of the benefits offered by the NACA riveting method compared to standard riveting performed with the use of the Finite Element Method. The influence of riveting on the residual stress state on the sheets' faying surface was 
analyzed. Three models were prepared (Fig. 4): the model of standard riveting with a countersunk rivet, the model of NACA riveting with a normal brazier rivet and the model of NACA riveting with a brazier rivet with a compensator.

a)

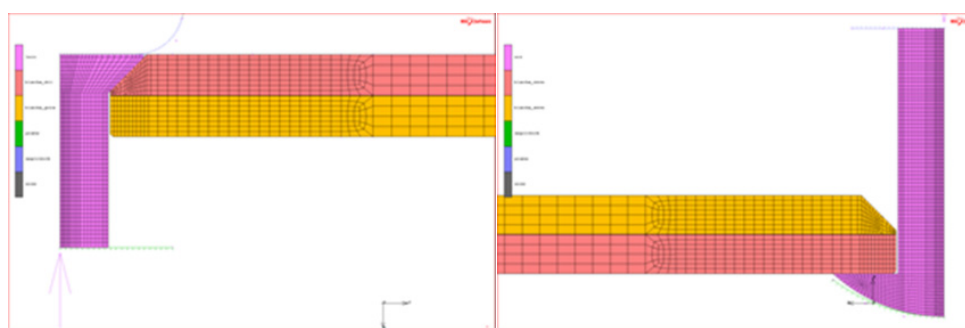

c)

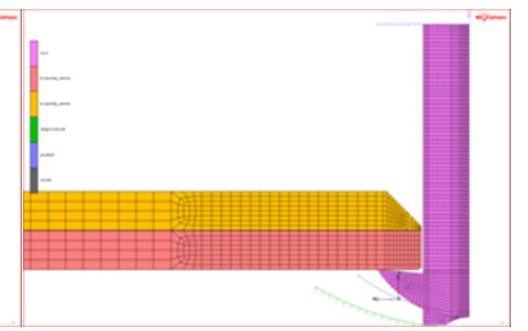

Fig. 4. FE model used in analysis: a) standard riveting with a countersunk rivet, b) NACA riveting with a normal brazier rivet, c) $N A C A$ riveting with a brazier rivet with compensator

The joint consisted of two 1,27 mm sheets made of 2024-T3 aluminum alloy and one of three types of rivets with diameter $3 \mathrm{~mm}$, namely the $90^{\circ}$ countersunk rivet according to the Polish branch standard BN-70/1121-04, the brazier rivet according to the Polish branch standard BN-70/1121-06 and the brazier rivet with a compensator according to the Russian standard OST $134040-79$ (Fig. 5). In all cases, the countersunk sheet angle was equal to $90^{\circ}$ and the rivet material was aluminum alloy 2117-T4. In the case of the NACA riveting, the value of the countersunk angle usually mentioned in the literature was $82^{\circ}$, but $88^{\circ}$ was also reported [8]. Probably, the reason for the change of the angle from $110^{\circ}$ or $100^{\circ}$ to $82^{\circ}$ was a problem with the proper filling of a countersunk [3, 7]. In this analysis, the $90^{\circ}$ angle was chosen since this modification did not change the idea of NACA riveting, probably do not influence the stress state strongly and experimental tests with such geometry was planned.
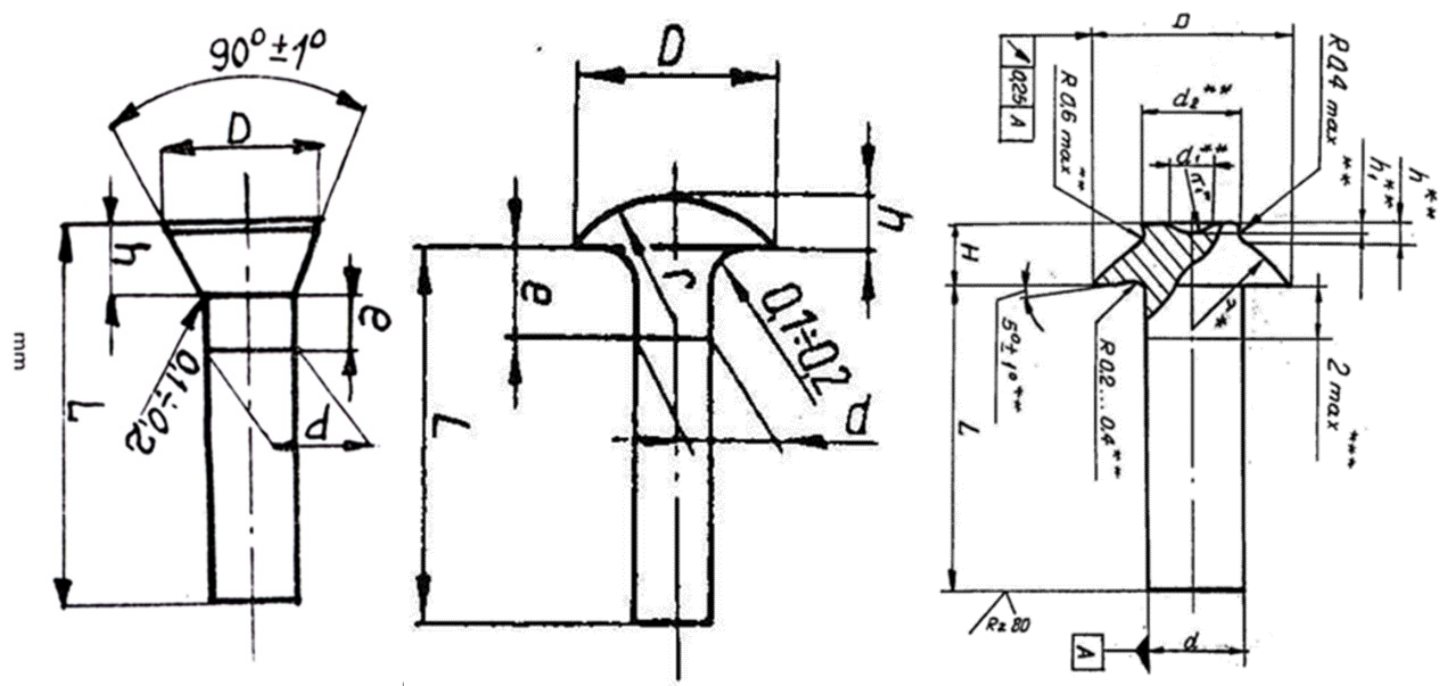

Fig. 5. Analyzed rivet types

Rivets with a compensator were developed in the former Soviet Union. A compensator is a small protruding part of a rivet head which is forced into the main part of the rivet head during riveting. This cause much higher hole expansion and so cold working and more beneficial stress system in a sheet on the rivet head side $[9,10]$. The configuration of the NACA riveting with a brazier rivet with a compensator was proposed by dr J. Kaniowski to solve the problem of cracks starting on the sheet on the rivet head side (inner) when the NACA riveting is used in lap joints. 
It is commonly accepted that the residual stress state around a rivet is of crucial significance for cracks nucleation. Residual stresses after riveting are compression radial stresses and, for some range of squeezing force, compression tangential stresses in the hole vicinity $[10,11]$. An increase in squeezing force enhances fatigue life of joint because it lead to change the tangential stress sign - from tension to compression, which prevents cracks nucleation. Usually, cracks nucleate near the faying surface of sheets. For these reasons, the analyzed configurations (Fig. 4) were compared based on the stress courses on the faying surfaces after riveting.

\section{FE MODELS}

The axisymmetric models were prepared for simulations of the force controlling riveting on a press. In all cases, the model consisted of two sheets (identical in all models), a rivet and tools (a hold-on and a press stamp modeled as rigid surfaces). During riveting, sheets are clamped together by special sleeve. This effect was modeled by the forces applied to the group of nodes on the sheet surface. The hold-on was fixed. The press stamp could move only in the rivet axis direction and it was controlled by the force that increased to the maximum and then it was released. Radial displacements of all nodes on the rivet axis were set to zero. Figure 6 shows all applied boundary conditions.

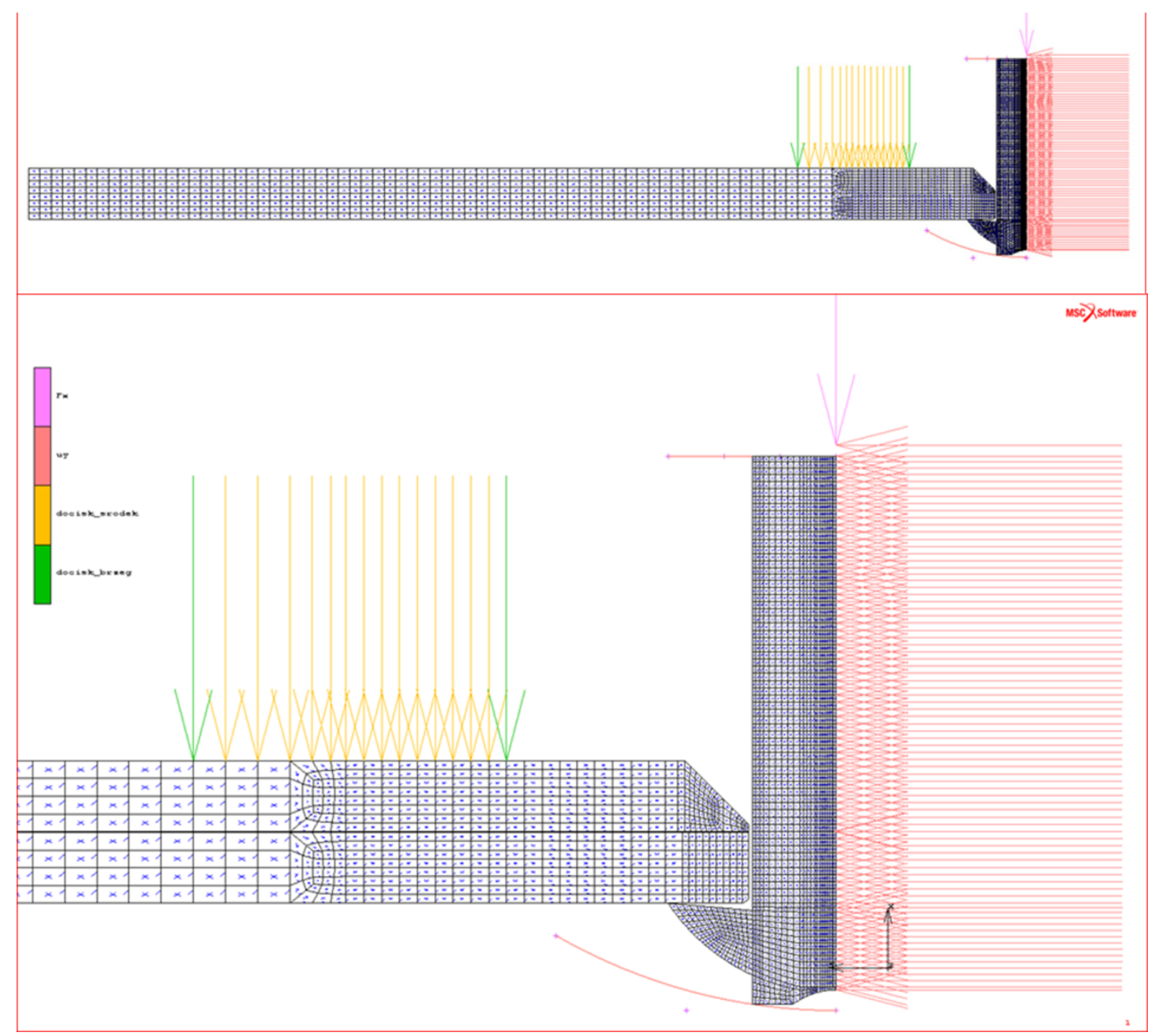

Fig. 6. Boundary conditions

Each model consisted of about 3000 linear four node-elements and 3300 nodes. The radius of the models was $50 \mathrm{~mm}$. Nonlinear implicit algorithm (MSC MARC) was used to take into account 
material plasticity, geometrical nonlinearity and contact phenomena. Nonlinear material models were used. The model of sheet material was developed based on material tests performed by the team led by prof. M. Skorupa of the AGH University in Krakow. In the case of the rivet material, the model used in [12] was adopted. Figure 7 presents stress-strain curves of the mentioned material models.

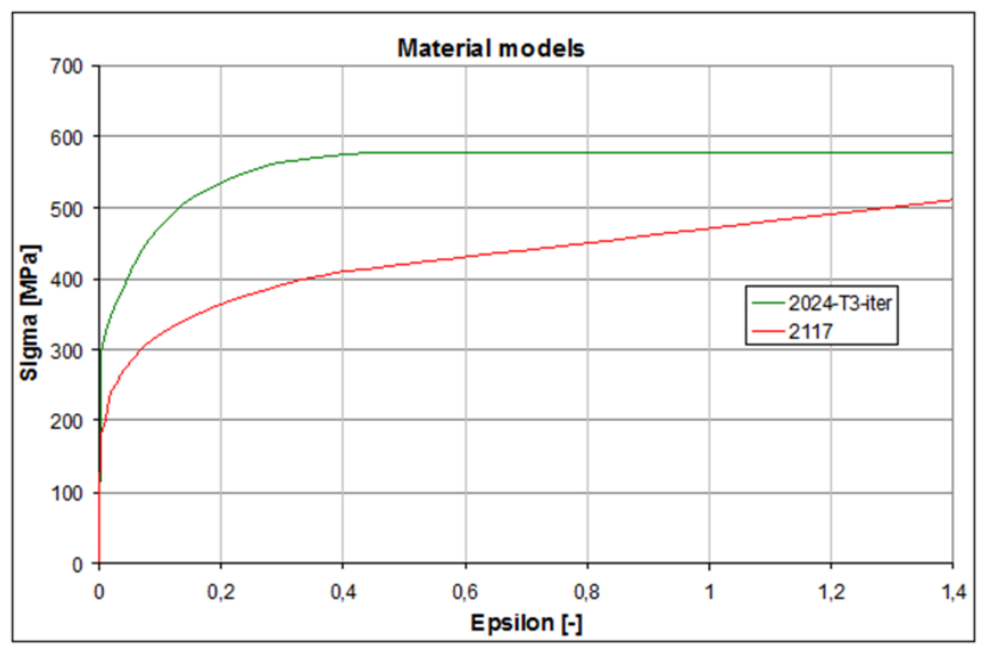

Fig. 7. Stress-strain curves of material models

The stick-slip friction model was chosen for contact interactions. In the case of friction between aluminum parts (sheets and rivet), friction coefficient equal to 0.42 for kinematic and 0.34 for static were adopted. In the case of steel (tools) - rivet interactions these coefficient were equal to 0,186 and 0,15 respectively. Values of coefficient were chosen based on [13].

\section{SELECTION OF THE RIVET LENGTH AND SQUEEZING FORCE}

Usually, dimensions of joints, such as the rivet length, hole and driven head diameter are specified in standards or a company's internal instructions. Parameters for a countersunk rivet were set based on [14]. The squeezing force value was selected to obtain the driven head diameter equal to 1,7 times the rivet shank diameter. It was higher than specified in the Polish standard but it was acceptable by instructions used in western aerospace industry and in compliance with the conclusion reached by Müller and Hart-Smith in [1]. In the case of the NACA riveting, the author was not able to obtain precise data. The unknown parameters were selected based on FE analyses. Simulation of the NACA riveting with the normal brazier rivet for three lengths was performed. The value of squeezing force which ensure filling of a countersunk was used for each rivet length. Then, residual stress courses on the sheets faying surface were compared. The shapes of driven heads and force values are presented in Figure 8.

a)

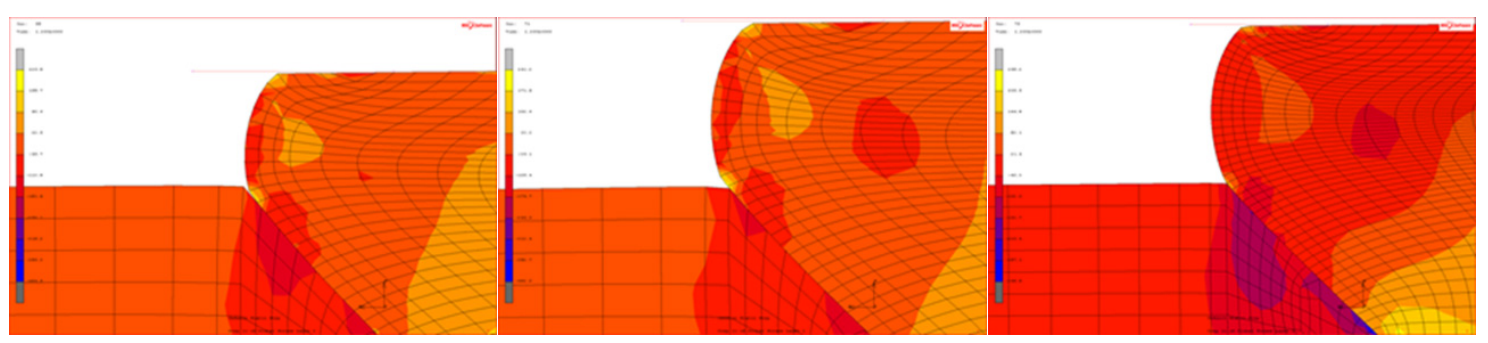

Fig. 8. NACA riveting. Filling of the countersunk for three rivet lengths and forces; a) $l=6 \mathrm{~mm}, F=20 \mathrm{kN}$, b) $l=7 \mathrm{~mm}, F=20 \mathrm{kN}, c) l=8 \mathrm{~mm}, F=17 \mathrm{kN}$ 


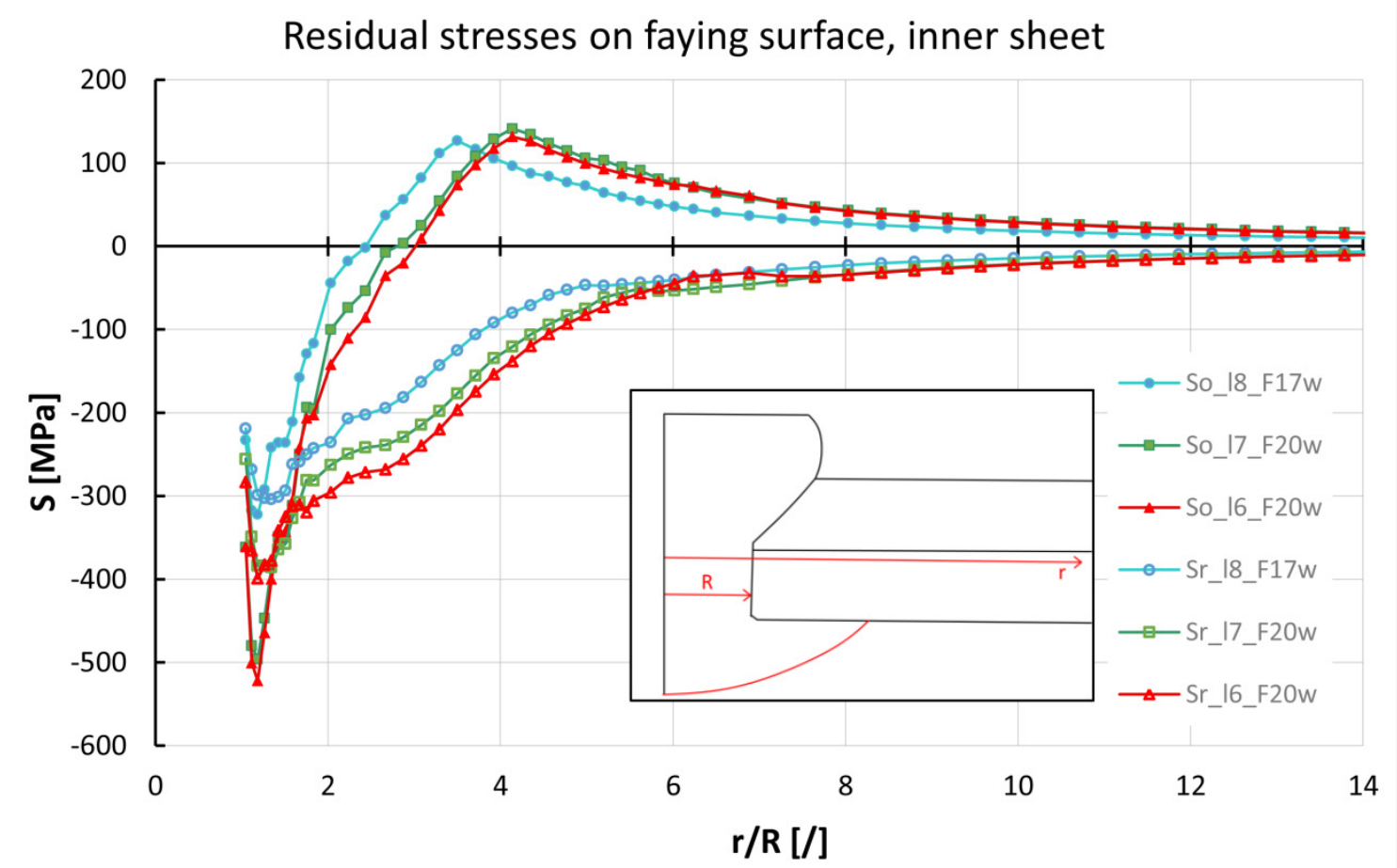

Fig. 9. Radial and tangential stress courses on the faying surface of the inner sheet.

The series name indicates the type of stress (Sr-radial, St-tangential), rivet length in $\mathrm{mm}$ and squeezing force in $k N$. The absolute radial coordinate ' $r$ ' is divided by the rivet shank radius ' $R$ '

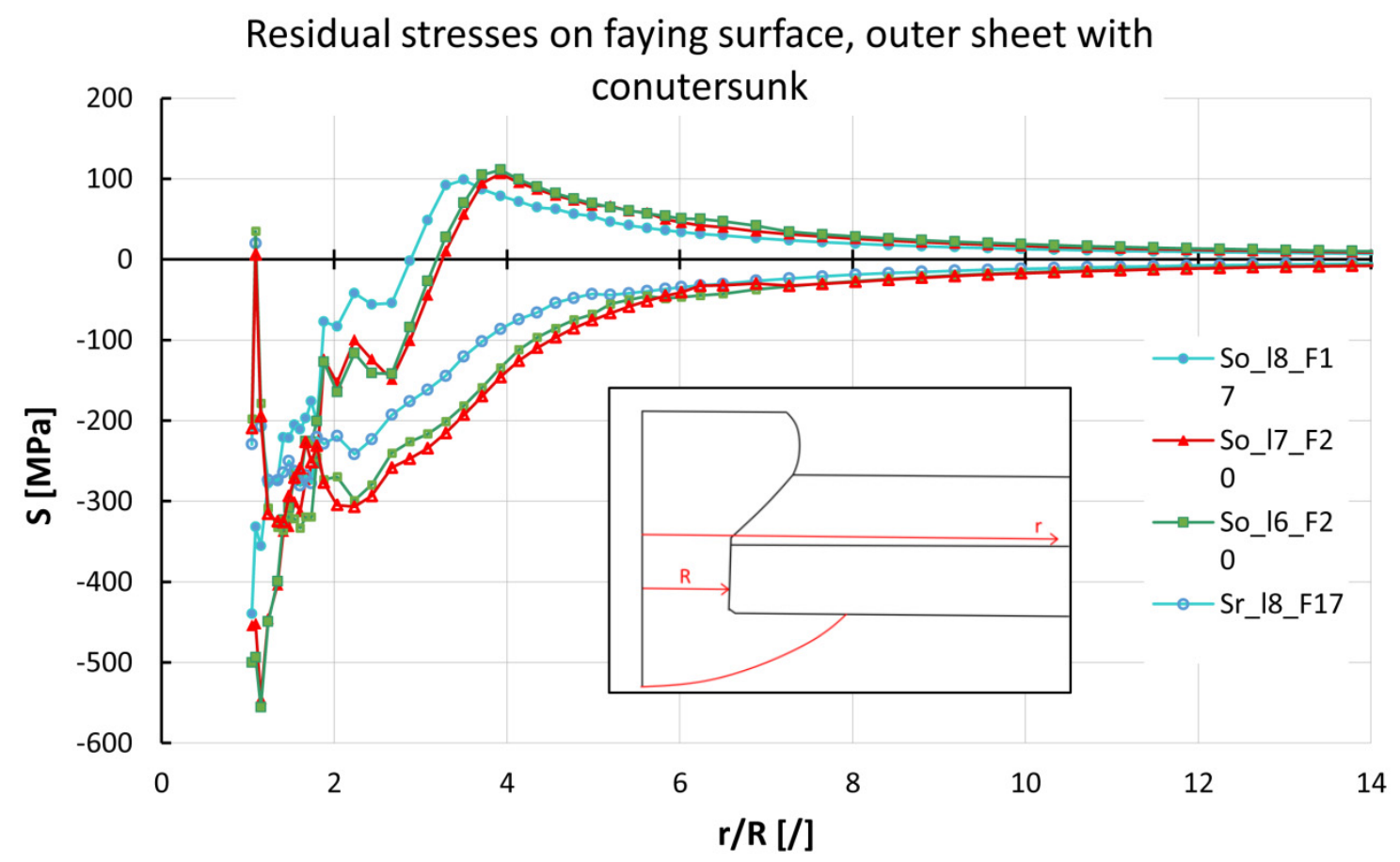

Fig. 10. Radial and tangential stress courses on the faying surface of the outer sheet (with a countersunk). The series name indicates the type of stress (Sr-radial, St-tangential), rivet length in $\mathrm{mm}$ and squeezing force in $\mathrm{kN}$. The absolute radial coordinate ' $r$ ' is divided by the rivet shank radius ' $R$ ' 
Figures 9-10 present radial and tangential stress courses on the faying surface of inner and outer sheet (with a countersunk). In the graphs, the absolute radial coordinate ' $r$ ' (distance from the rivet axis) is divided by the rivet shank radius ' $R$ '. Series names indicate the type of stress, rivet length and squeezing force.

There are no big differences in the courses of residual stresses for the analyzed cases. In particular, similar are the curves for the rivets with the lengths of 7 and $8 \mathrm{~mm}$, riveted with the same force. The length of $8 \mathrm{~mm}$ was selected due to the lowest force value.

\section{RESULTS}

Riveting simulations were performed for three cases mentioned in Point 3 above. It was necessary to increase squeezing force to $20 \mathrm{kN}$ for the rivet with a compensator to obtain filling of countersunk. This type of rivets usually requires of higher force. Table 1. presents deformations and stresses for the analyzed models.

Table 1. Deformation and stresses after riveting

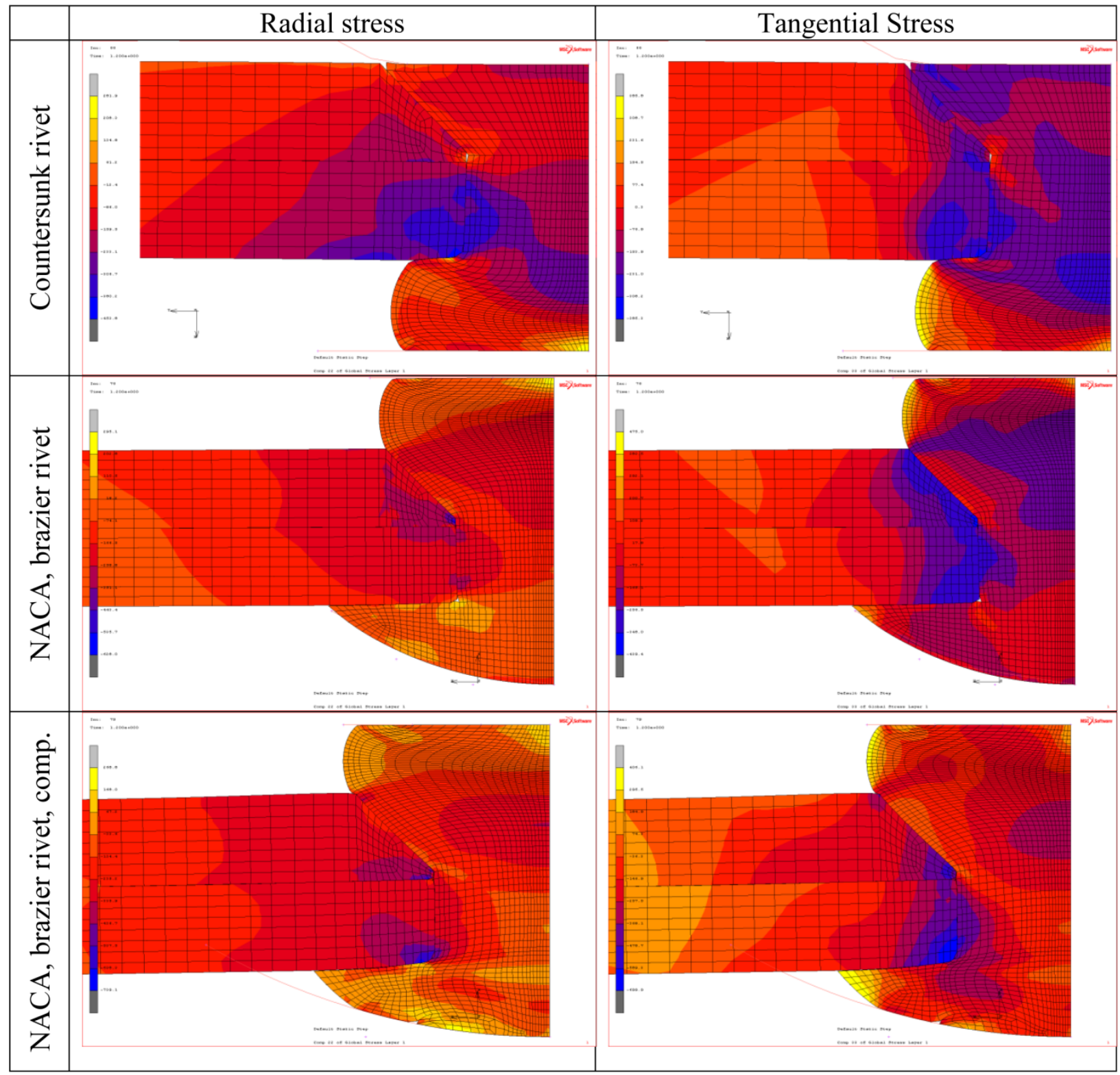




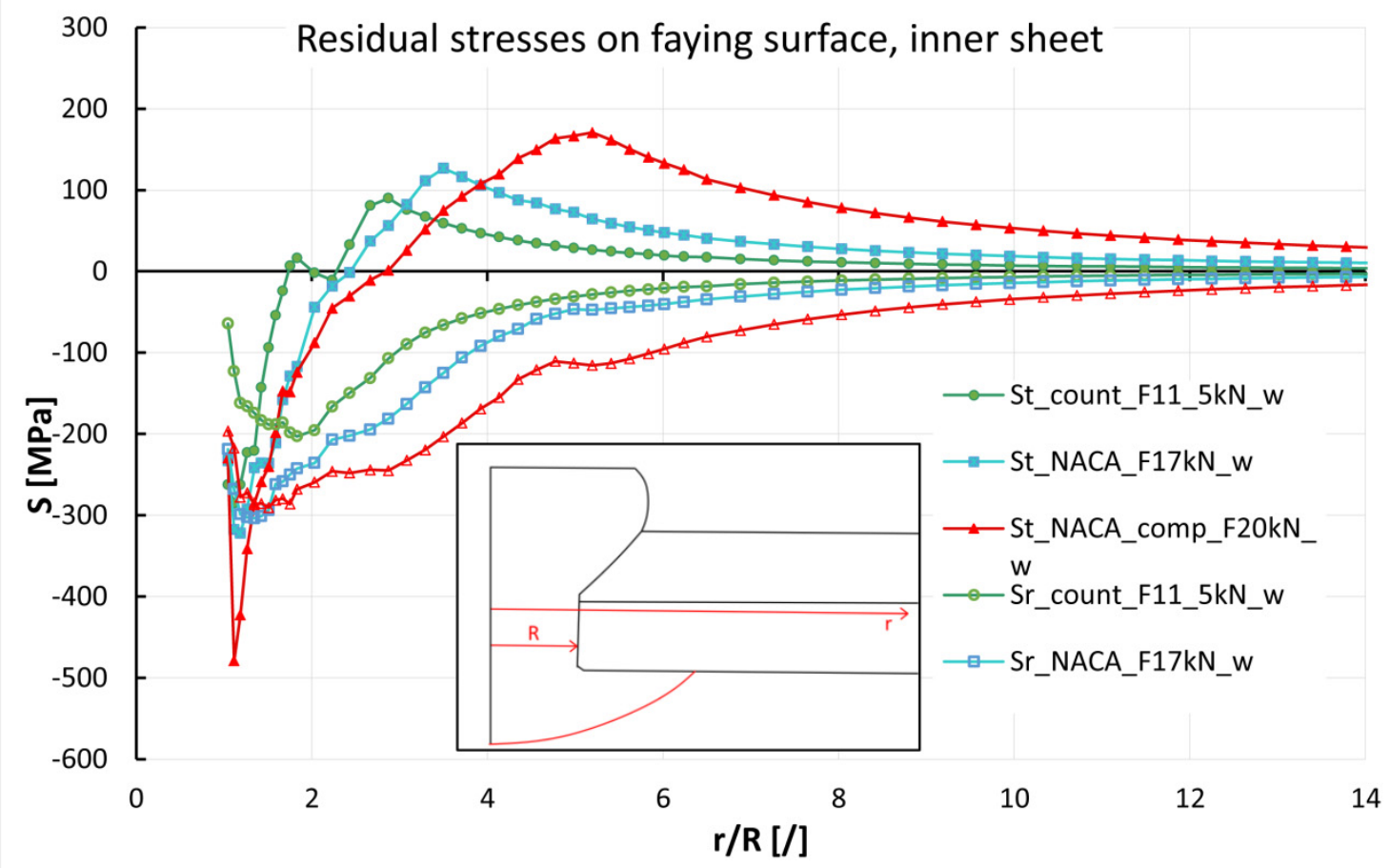

Fig. 11. Radial and tangential stress courses on faying surface of the inner sheet. The series name indicates the type of stress (Sr-radial, St-tangential), type of riveting (cout-coutersunk rivet, NACA$N A C A$ riveting with a brazier rivet, $N A C A$ comp-NACA riveting with a brazier rivet with compensator) and squeezing force in $k N$. Absolute radial coordinate ' $r$ ' is divided by the rivet shank radius ' $R$ '

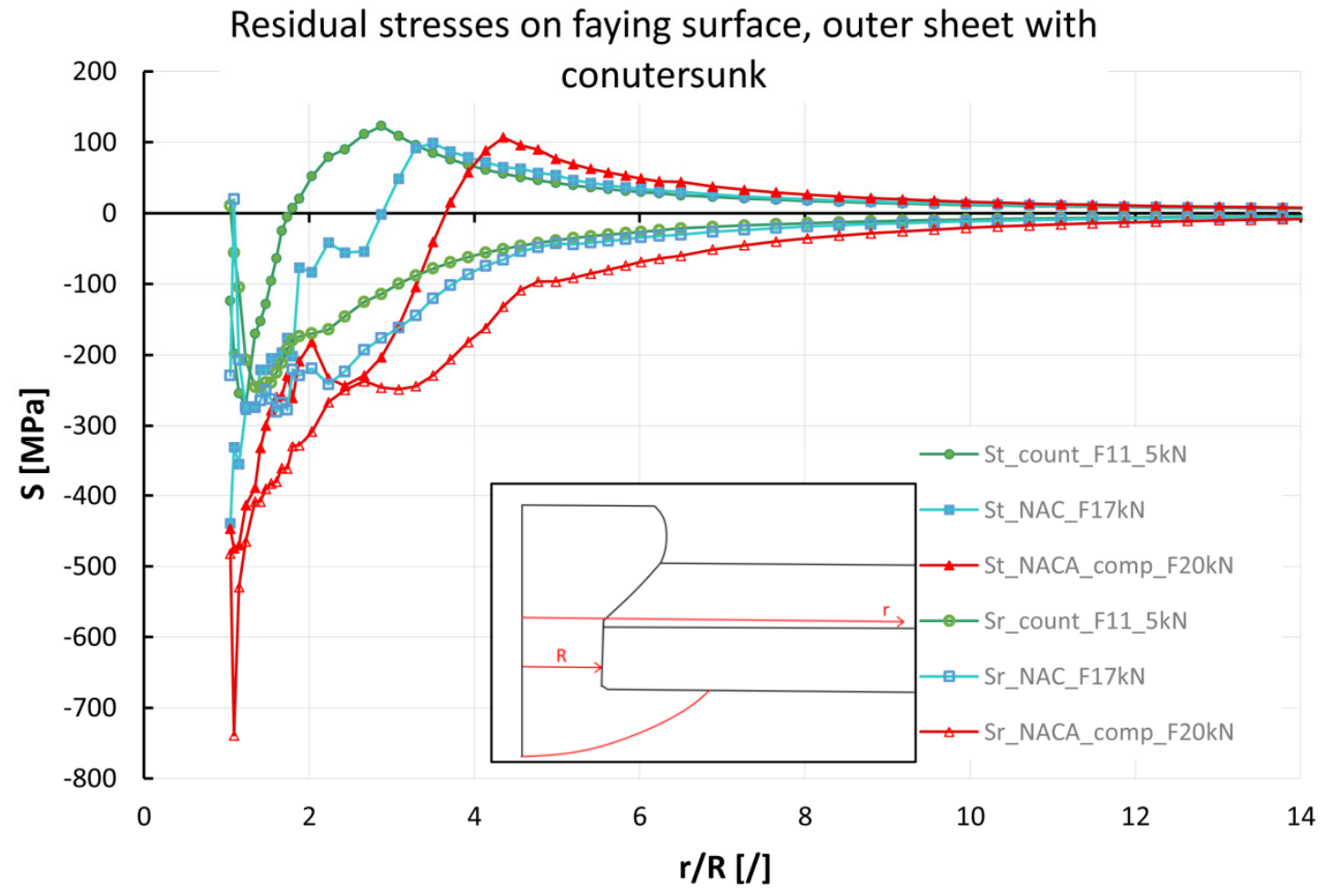

Fig. 12. Radial and tangential stress courses on the faying surface of the inner sheet. The series name indicates type of stress (Sr-radial, St-tangential), type of riveting (cout-coutersunk rivet, NACA-NACA riveting with a brazier rivet, $N A C A$ _comp-NACA riveting with brazier rivet with compensator) and squeezing force in $k N$. Absolute radial coordinate ' $r$ ' is divided by the rivet shank radius ' $R$ ' 
In the case of the countersunk rivet, radial and tangential stresses were significantly lower in the outer sheet (with a countersunk) than in the inner sheet, which is a known disadvantage of this type. In the case of the normal brazier rivet, stresses were higher on the outer sheet but the differences were not so big. In the case of the brazier rivet with a compensator, stresses were higher in the inner sheet which was caused by a compensator. When a compensator is forced into the main part of a rivet head, it increases radial expansion on this side. More homogenous stresses along the sheets thickness were obtained for the brazier rivet with a compensator in the case of radial stresses and for the normal brazier rivet in the case of tangential stresses. Slight sheets bend can be noticed for the rivet with a compensator.

Figures 11-12 present radial and tangential stress courses on the faying surface of the inner and outer sheet (with a countersunk).

Radial compressive stresses were higher in the case of the NACA riveting in both sheets. Generally, compressive stresses (radial and tangential) are favorable since they prevent cracks nucleation and growth. In the inner sheet, the NACA riveting caused that the point where tangential stresses change the sign from compression to tension and the maximum of tension stresses are farther from the rivet. Unfortunately, these extremes were higher too. In the outer sheet, this shift of the compression region ranges and the maximum tangential stress positions was bigger. Moreover, these extremes were lower, which is beneficial from the fatigue point of view. The mentioned effect of the NACA riveting were stronger for the rivet with a compensator except that the maximum tangential stress in the outer sheet was slightly higher for the rivet with a compensator than for the normal brazier rivet. Since the rivet with a compensator required a higher squeezing force it was not clear what was the effect of a compensator and what was the effect of a higher force.

\section{CONCLUSIONS}

The results of FE simulations of standard riveting with a countersunk rivet and the NACA riveting in two configurations were compared based on stress courses on the sheets faying surface. The analysis indicated beneficial influence of the NACA riveting in the outer sheet (with a countersunk) and disadvantageous influence in the inner sheet, especially in the case of the rivet with a compensator.

Using the rivet with a compensator did not yield the expected results similar to those reported in [10], where decrease and shift outside the rivet of the maximum tangential stress were obtained. In that paper, PA25 aluminum alloy was used, but in [9], the change of the rivet material from the PA25 to the 2117-T4 alloy improved fatigue characteristics of riveted joints.

The presented simulations did not include the milling of a protruding part of the driven head, which is the last operation of the NACA riveting method. Probably, this process mainly influence axial stresses which are not considered in this analysis. There are also some differences between described simulations and the original NACA procedure, which is not known to the author in details.

The results of the presented calculations are equivocal. Further, more detailed theoretical and experimental investigations into the NACA riveting are required to analyze of its mechanism, determine optimal parameters and verify influence on fatigue life.

\section{Acknowledgments}

The work was financed from the scientific research resources of the Institute of Aviation. The author expresses his gratitude to Dr L. J. Hart-Smith for his inspiriting paper and remarks about the NACA riveting method. 


\section{REFERENCES}

[1] R.P.G. Müller, L.J. Hart-Smith, Making fuselage riveting lap splices with 200-year crackfree fatigue life. ICAF 97', Fatigue in new and ageing aircraft. Proceedings of the I9-th Symposium of the International Committee of Aeronautical Fatigue 1997, Edinburgh, EMAS Publishing, pp.499-522, (1997).

[2] Bartone, L. M., Mandel, M., W. Tensile Tests of NACA and Conventional MachineCountersunk Flush Rivets. UNT Digital Library.

http://digital.library.unt.edu/ark:/67531/metadc61751/. Accessed August 30, 2016, (1944).

[3] Lundquist E., Gottlieb R. A study of the tightness and flushness of machine-countersunk rivets for aircraft, NACA Wartime Report L-294 UNT Digital Library.

http://digital.library.unt.edu/ark:/67531/metadc61748/. Accessed August 30, 2016, (1942).

[4] Maney G. A., Wyly, L T. Fatigue strength of flush-riveted joints for aircraft manufactured by various riveting methods. UNT Digital Library. http://digital.library.unt.edu/ark:/67531/metadc61854/. Accessed August 30, 2016, (1945).

[5] Hartman, A.: A comparative investigation on the investigation on the influence of sheet thickness, type of rivet and number of rivet rows on the fatigue strength at fluctuating tension of riveted single lap joints of 24 ST Alclad sheet and 17 S rivets. Report NLR M.1943. NLR, Amsterdam, (1954).

[6] Oldersma, A.: Fatigue of riveted joints. A literature survey and statistical analysis of existing test data. Report NLR CR 92401 L. NLR, Amsterdam, (1992).

[7] LJ Hart-Smith, Forgotten attributes of NACA rivet installations and ice-box rivets, 7th. joint FAA/DoD/NASA Aging Aircraft Conference, New Orleans, Louisiana, September 8-11,2003, Boeing paper PWDM03-0130, (2003).

[8] Skorupa A., Skorupa, M., Riveted lap joints in aircraft fuselage: design, analysis and properties. Springer Science \& Business Media, (2012).

[9] Skorupa M., Skorupa A., Machniewicz T., Korbel A., Effect of production variables on the fatigue behaviour of riveted lap joints, International Journal of Fatigue, 32 (2010) pp.9961003, (2010).

[10] Wronicz, W., Kaniowski J., Experimental and Numerical Study of Strain Progress During and After Riveting Process for Brazier Rivet and Rivet with Compensator-squeezing force and rivet type effect. Fatigue of Aircraft Structures 2011.3, pp.166-190, (2011).

[11] Muller R. An Experimental and Analytical Investigation on the Fatigue Behavior of Fuselage Riveted Lap Joint. Ph.D. thesis, TU Delft, Netherlands, (1995).

[12] Fárek J.: FE-Modelling Methodology of Riveted Joints. Czech Aerospace Proceedings. Journal For Czech Aerospace Research, No 2/2010, pp.12-16, (2010).

[13] ASM Handbook, Volume 18, Friction, Lubrication, and Wear Technology, (1995)

[14] Kaniowski, J. Comparison of Selected Rivet and Riveting Instructions, Fatigue of Aircraft Structures 2014.6, pp.39-62, (2014). 